Relations industrielles

Industrial Relations

\title{
Double caractère du travail
}

Volume 1, numéro 9, mai 1946

URI : https://id.erudit.org/iderudit/1023956ar

DOI : https://doi.org/10.7202/1023956ar

Aller au sommaire du numéro

Éditeur(s)

Département des relations industrielles de l’Université Laval

ISSN

0034-379X (imprimé)

1703-8138 (numérique)

Découvrir la revue

Citer cet article

(1946). Double caractère du travail. Relations industrielles / Industrial Relations,

1(9), 6-6. https://doi.org/10.7202/1023956ar

Tous droits réservés (C Département des relations industrielles de l’Université Laval, 1946
Ce document est protégé par la loi sur le droit d'auteur. L’utilisation des services d'Érudit (y compris la reproduction) est assujettie à sa politique d'utilisation que vous pouvez consulter en ligne.

https://apropos.erudit.org/fr/usagers/politique-dutilisation/ 


\section{DOUBLE CARACTÈRE DU TRAVAIL}

Le travail possède un caractère à la fois individuel et social. Le caractère individuel du travail n'échappe à personne, puisque l'ouvrier doit pouvoir vivre avec sa famille du fruit de son labeur ; s'il en était autrement, la presque totalité des humains seraient condamnés à vivre dans des conditions de misère et de dégradation. Pour ce qui est du caractère social du travail, on peut se demander en quoi il consiste.

Dans les temps primitifs, l'homme travaillait uniquement, ou presque, pour gagner sa subsistance et celle des siens. Il produisait ce qu'il pouvait consommer et consommait ce qu'il produisait. Mais même à cette époque où les conditions de vie étaient plus que modestes, cet homme eut tôt fait de s'associer à d'autres hommes ; les fonctions se divisèrent; le travail spécialisé vit le jour : l'un devint bûcheron ; l'autre, ouvrier-maçon ; un troisième, berger, ete. Il arriva alors que chacun fabriquant une espèce différente de produit et en plus grande quantité qu'il n'en pouvait consommer, on vit apparaître sur le marché les premières denrées économiques; c'est dès lors que le travail devint un facteur de richesse sociale.

L'association des travailleurs, qui en ces temps lointains se dessinait à peine mais quii n'a cessé de croître avec les siècles, est maintenant la grande loi des sociétés modernes, soulignant ainsi le caractère social du travail. Nous savons que si la société n'est pas constituée en un vaste corps bien organisé, que si les diverses professions, si étroitement solidarres, ne coopèrent et ne se complètent mutuellement; surtout, que si le capital et le travail ne se fusionnent de quelque manière en vue d'atteindre à l'unité d'action, l'activité humaine devient stérile.

L'homme recherche l'association au travail pour la pratique technique de son métier - division du travail, travail à la suite, travail spécialisé - mais c'est aussi une tendance naturelle chez lui de tenter de s'associer à d'autres travailleurs; l'histoire des corporations au moyen âge nous en fournit d'ailleurs la preuve, et aujourd'hui, il nous est donné de le constater nous-mêmes en voyant les hommes s'organiser en syndicats et en corporations.

Le syndicalisme bien compris et légalement pratiqué est le meilleur moyen qu'ont les travailleurs de satisfaire ce besoin inné de se rápprocher, de mettre en commun leurs aspirations, leurs droits et devoirs, leurs idées, dans le domaine du travail : voila encore qui illustre bien le caractère profondément social du travail. De plus, l'activité humaine que nous appelons TRAVAIL est sociale, tout comme sa FIN SOCIALE, en ce que le travail doit contribuer, et contribue en effet, au bien de la collectivité ; il n'y parvient toutefois que s'il est organisé, protégé et coordonné en vue du bien commun.

Pour atteindre ce dernier résultat, cependant, il faut l'effort conjugué de toutes les volontés individuelles, conscientes de cette fin sociale. Quand ces volontés s'associent pour un même but en corps professionnels organisés ; quand, au-dessus de ces groupements, il s'établit un organisme supérieur pour représenter les intérêts généraux, assez compétent pour les définir et les réglementer, suffisamment fort pour les diriger efficacement vers le bien commun, alors seulement le travail revêt vraiment un caractère à la fois individuel et social.

Le sens social ne peut être compris du libéral pétri d'individualisme, imbu de son propre " moi »; il ne peut l'être non plus du communiste dont c'est la théorie que la personne humaine doive se perdre dans le tout social et devenir ainsi une misérable unité dans le troupeau humain. Ce sens social ne peut être compris que du patron qui connaît la justice et veut la pratiquer ; aussi, du travailleur qui, a une juste conception du sens social, à laquelle il sait ramener tous ses actes.

Il est certain que le travail est dur et coûte des efforts à qui doit l'accomplir; mais il est vrai aussi que dans l'ordre surnaturel, il remplit un bien beau rôle : celui de rapprocher des puissances opposées, portées à la division. Ceci nous explique pourquoi, dans l'antiquité paienne, on professait le mépris du travail, concept qu'un vrai chrétien ne peut accepter.

Les philosophes paiens, qui louaient le travail intellectuel, dédaignaient le travail manuel ou corporel et il était temps que le christianisme vint donner une leçon à ces orgueilleux et que le monde connut enfin le vrai sens du travail, tant manuel qu'intellectuel, car si, intrinsèquement, celui-ci est supérieur à celui-jà de par son but plus noble et sa réalisation plus indépendante des facteurs matériels, il n'en reste pas moins que le travail vaut surtout par l'esprit qui anime celui qui l'exécute. En effet, tous les travailleurs, manuels ou intellectuels, possèdent la même dignité, égale en principe, mais qui est accrue ou diminuée selon que le devoir est accompli de façon plus ou moins parfaite, plus ou moins honnête. En un mot, la dignité du travail est la dignité du Christ ouvrier, la dignité même de Dieu.

Voz Patronal, oct. 1945 (Traduction).

\section{GARE A LA TACTIQUE COMMUNISTE (Suite de la page 1)}

que la masse ouvrière doit joindre les rangs du parti communiste. $\mathrm{Au}$ contraire, si les employeurs considèrent les unions comme des organismes de collaboration économique et sociale, jamais les communistes n'auront l'opportunité de contrôler le mouvement syndical en se substituant aux chefs responsables et modérés.

Avant de confondre le syndicalisme avec le communisme, on devrait réfléchir à cette tactique des communistes. Au point de vue tactique, ils peuvent nous en apprendre beaucoup.

\section{BEWARE OF COMMUNISTIC TACTICS}

$$
\text { (From page 1) }
$$

Labour Movement by taking the place of responsible and moderate leaders.

Before mistaking Trade-Unionism for Communism, let us be careful. On such matters as tactics, the Communists could teach us many things. 